\title{
ATIVIDADES ANTRÓPICAS NA MICROBACIA DO CÓRREGO DA BARRINHA, MUNICÍPIO DE PIRASSUNUNGA, ESTADO DE SÃO PAULO, BRASIL
}

\section{ANTHROPOGENIC ACTIVITIES IN THE MICRO-BASIN OF THE BARRINHA STREAM, PIRASSUNUNGA COUNTY, SÃO PAULO STATE, BRAZIL}

\section{André Gustavo Mazzini Bufon ${ }^{1}$, Sâmia Maria Tauk- Tornisielo², José Sávio Colares de Melo, Paulo Milton Barbosa Landim $^{3}$}

${ }^{1,2}$ Centro de Estudos Ambientais, UNESP, UNESP. Av. 24-A, 1515 Bela Vista, 13506-900, Rio Claro, SP. Fone: 19-35269493. e-mail: seb@rc.unesp.br

${ }^{3}$ Instituto Chico Mendes de Conservação da Biodiversidade, Centro Nacional de Pesquisa e Conservação de Peixes Continentais. Rodovia SP 201, km 6,513630-970 -

Pirassununga, SP - Brasil - Caixa-Postal: 64

Telefone: (19) 35651299 ramal: 229 Fax: (19) 35651318.

${ }^{3}$ Departamento de Geologia Aplicada. Instituto Geociências e Ciência Exatas UNESP Av. 24 A, 1515, Bairro Bela Vista - Rio Claro - SP. e-mail:

plandim@rc.unesp.br

\section{RESUMO}

O objetivo deste estudo foi avaliar o uso e ocupação do solo da microbacia do córrego da Barrinha no intuito de identificar a situação existente. A microbacia do córrego da Barrinha está localizada em Cachoeira de Emas, no município de Pirassununga, Estado de São Paulo, com área estimada em 862 ha. Está localizada na bacia do rio Mogi-Guaçu onde se situa o Instituto Chico Mendes de Conservação da Biodiversidade, Centro Nacional de Pesquisa e Conservação de Peixes Continentais. A área onde se localiza está sob forte influência demográfica, recortada por estrada asfaltada e limitada por dois distritos urbanos (Cachoeira de Emas e Vila Santa Fé), essa microbacia sofre diretamente os efeitos da pressão antrópica. O manejo de culturas faz com que durante alguns meses do ano o solo se apresente sem proteção. Isso, combinado com as características morfológicas e de morformetria, permite o processo erosivo laminar, o que promove a ocorrência de sulcos, ravinas e voçorocas à jusante. Além disso, ocorre também a presença de erosão regressiva em taludes, marcada por sulcos em ravinas, pronunciadas em área de terraço recente. A situação da perda de solo, ocasionada principalmente pelo manejo mal orientado ou pela prática agrícola em zonas de preservação permanente, como o nicho da nascente, são fatores que tendem a contribuir para a perda de solo fértil. O plantio de cana-de-açúcar, a rotação de cultura, bem como a prática da mineração de saibro intensificam o assoreamento no canal do córrego da Barrinha.

Palavras-chave: Microbacia. Córrego da Barrinha. Atividades antrópicas. Impactos ambientais negativos. 


\begin{abstract}
The purpose of this study was to evaluate the use and occupation of the Barrinha stream microbasin, in order to identify the local environment conditions. The micro-basin is located in Cachoeira de Emas, Pirassununga County, São Paulo State, with an estimated area of 862 ha. This micro-basin is located in the Mogi Guaçu river basin where situated the Chico Mendes Institute for Biodiversity Conservation, National Center for Research and Conservation of Fish Continental. The area is located is heavily influenced by demographic, crossed by paved road and bounded by two urban districts (Cachoeira de Emas and Vila Santa Fe), the watershed suffers the effects of anthropogenic pressure directly. The management of crops results for a few months of the year the soil presenting without protection. This combined with the morphological characteristics allow laminar erosion process that promotes the occurrence of ridges, ravines and gullies downstream. Moreover, there is the presence of regressive erosion on slopes, in ravines marked by grooves, pronounced in recent terrace area. The situation of soil loss, mainly caused by management or the misguided agricultural practice in areas of permanent preservation, as the niche of the spring, are factors that tend to contribute to the loss of fertile soil. The planting of sugar cane, crop rotation, and the practice of gravel mining intensify the siltation in the channel of the Barrinha steam.
\end{abstract}

Keywords: Micro-basin. Barrinha stream. Anthropogenic. Negatives environmental impacts

\title{
1. INTRODUÇÃO
}

O problema da degradação ambiental é bastante antigo, confundindo-se no tempo e no espaço com a evolução e a capacidade modificadora do ser humano em relação ao ambiente. A apropriação, o uso e a exploração do meio ambiente são realizados, em geral, de forma indiscriminada, levando em consideração tão somente atender às necessidades com resultados imediatos e privilegiando políticas desenvolvimentistas que contemplam apenas os aspectos econômicos e financeiros. Atualmente, a Sociedade percebe que o desenvolvimento econômico somente atingirá um ponto máximo e assim permanecerá se for conciliado com o respeito à qualidade ambiental, ao que se denomina desenvolvimento sustentável (NASCIMENTO e GALIANO, 1999).

Em escala temporal, tendo em vista a própria evolução do uso do solo, pode-se considerar o caráter de transitoriedade das feições erosivas lineares e de sedimentação correspondentes. Os depósitos tecnogênicos formados pela retenção dos sedimentos no reservatório correspondentes ao seu assoreamento, considerada a escala de observações hidrológicas, constituem, o destino final dos sedimentos (OLIVEIRA, 1994).

A quantidade de sedimentos provenientes de uma bacia contribuinte e, por exemplo, retida dentro de um reservatório com eficiência plena de retenção, corresponde à quantidade total de partículas desprendidas nas áreas-fonte "perdas de solo" da bacia, menos a quantidade de partículas que é depositada entre as áreas-fonte e o reservatório, para um dado período (DUNNE e DIETRICH, 1982).

A identificação e a compreensão dos efeitos da pressão antrópica sofrida pela microbacia do córrego da Barrinha são necessárias para subsidiar o planejamento de políticas públicas voltadas à recuperação das áreas degradadas. Assim, o objetivo deste estudo foi avaliar o uso e ocupação do solo da microbacia do córrego da Barrinha, estado de São Paulo, no intuito de identificar a situação existente. 


\section{MATERIAL E MÉTODOS}

A microbacia do córrego da Barrinha está localizada em Cachoeira de Emas, no município de Pirassununga, Estado de São Paulo, em $21^{\circ} 55^{\prime} 35^{\prime \prime} \mathrm{S}$ e $47^{\circ} 22^{\prime} 00^{\prime}$ ' W, e $21^{\circ} 57^{\prime} 30^{\prime \prime}$ S e $47^{\circ} 24^{\prime}$ 00" W, a $575 \mathrm{~m}$ acima do nível do mar, com extensão de $4 \mathrm{~km}$ e área estimada em 862 ha. Esta microbacia pertence à bacia do rio Mogi-Guaçu, constituída de 9 propriedades, sendo que 259 ha (40\%) da área é de propriedade da União desde 1938, adquirida da Fazenda Graciosa para a criação da antiga Estação Experimental de Biologia e Piscicultura (EEBP) e, em 1979, repassada para o CEPTA/IBAMA - Centro de Pesquisa e Conservação de Peixes Continentais/Instituto de Meio Ambiente e dos Recursos Naturais Renováveis, atualmente, Instituto Chico Mendes de Conservação da Biodiversidade (ICMBio/MMA). Com localização em área tendo forte influência demográfica, recortada por estrada asfaltada e limitada por dois distritos urbanos (Cachoeira de Emas e Vila Santa Fé), essa microbacia sofre diretamente os efeitos da pressão antrópica (SILVA et al., 1994).

A área da microbacia do córrego da Barrinha é dividida em pequenas propriedades rurais, as quais desenvolvem diversas atividades agropecuárias, como a plantação de cítricos, cana-de-açúcar, forrageiras de inverno entre outras, além de criação de gado bovino e atividades de mineração, como a extração de areia. No Instituto Chico Mendes há instalações de aquicultura.

A microbacia em estudo tem coeficiente de escoamento superficial ("runoff") igual a 0,40 mm em função do tipo de solo, cobertura vegetal e declividade. A intensidade de chuva de determinado tempo de recorrência e de duração igual ao tempo de concentração da bacia é de 72 $\mathrm{mm} / \mathrm{h}$. Na área da nascente, o córrego sofreu retificação através da construção de vários canais artificiais, com o objetivo de melhorar a distribuição da água, tornando a área agriculturável. Esses canais estendem-se em várias direções. A extensão do córrego é de $3.217 \mathrm{~m}$, da nascente até desembocar na represa Velha do Instituto Chico Mendes. Essa represa foi construída no final do ano de 1939 e a água alcançou seu nível atual em fevereiro de 1940. Uma barragem de $300 \mathrm{~m}$ de comprimento, feita de terra, represou a água procedente de três riachos (KLEEREKOPER, 1941). O córrego da Barrinha, que tem sua nascente fora da área do Instituto Chico Mendes é um desses três riachos e atualmente é o principal contribuinte dessa represa.

Com uma superfície de aproximadamente 5 ha e um sistema de comporta que permite seu esvaziamento total, a represa Velha é atualmente a responsável por grande parte do abastecimento dos tanques, viveiros e laboratórios do Instituto Chico Mendes, onde a água é utilizada em experimentos de pesquisa de criação de peixes, e o efluente dessa atividade despejado no rio MogiGuaçu. A Figura 1 apresenta uma vista aérea desse Centro, onde se visualiza a represa Velha ao fundo, uma mata ciliar no entorno da represa e as instalações de viveiros de piscicultura. Esta figura mostra uma visão panorâmica da microbacia do córrego da Barrinha.

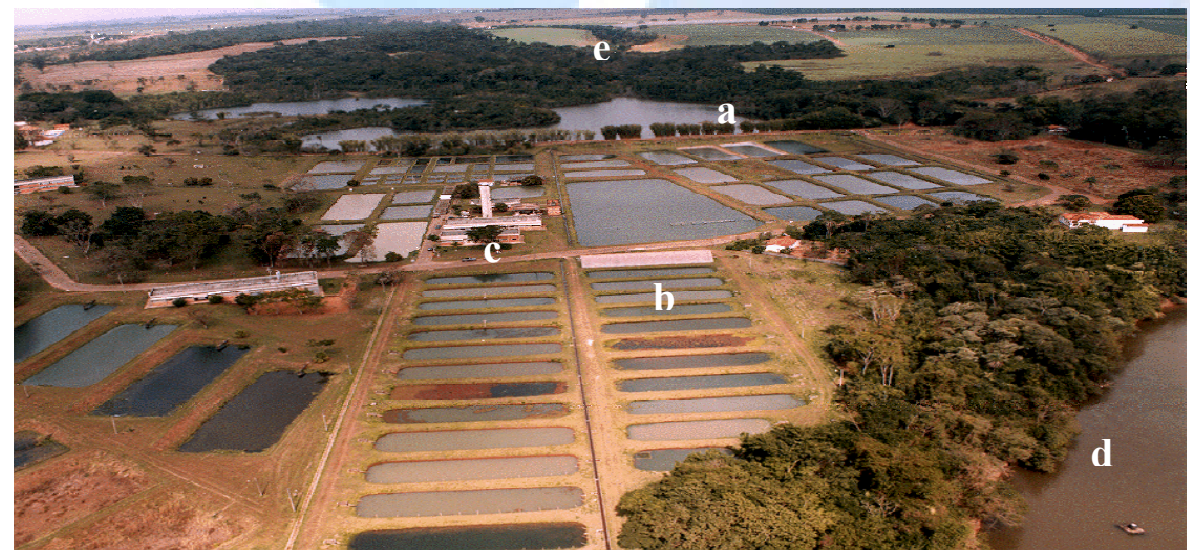

Figura 1. Vista aérea da microbacia do córrego da Barrinha, mostrando a represa Velha: (a) represa Velha; (b) tanques e viveiros de piscicultura; (c) laboratórios; (d) rio Mogi-Guaçu; e (e) nascentes. Fonte: Bufon (1999). 
As características climáticas do município de Pirassununga, pela classificação de Köpen, são do tipo CWA (clima subtropical de altitude), com inverno seco e chuvas no verão. A temperatura dos meses mais quentes (janeiro e fevereiro) é superior a $22^{\circ} \mathrm{C}$ e a do mês mais frio (julho), inferior a $18{ }^{\circ} \mathrm{C}$. O total médio de chuva do mês mais seco não ultrapassa $30 \mathrm{~mm}$ (LOMBARDI NETO e CAMARGO, 1992). A pluviosidade anual é de $1.410,99 \mathrm{~mm}$, média calculada para os últimos doze anos, dados fornecidos pela Divisão de Meteorologia Aeronáutica (DMET), localizada na Academia da Força Aérea (AFA) de Pirassununga/SP.

A caracterização do uso e ocupação do solo foi feita baseada em dados coletados em campo, em visitas na área da microbacia. As informações foram obtidas por meio de entrevistas informais com os antigos e atuais proprietários, além de visita a cada propriedade, considerando 3 grandes unidades para a microbacia do córrego da Barrinha, setor de alto curso, médio curso e baixo curso.

Considerou-se como base cartográfica um mapa aerofotogramétrico, fotos de julho de 1992, restituído no aparelho WILD B8S na escala 1:5000 em maio de 1995, em projeção UTM (SAD 69), e a fotointerpretação da empresa PLANTERRA LTDA, fornecido pelo ICMBio/MMA. A digitalização da carta obedeceu à norma técnica NBR 14166 (Rede de Referência Cadastral de 1998) e foi realizada na mesa CARTALINX, tendo sido digitalizadas as informações sobre o uso e ocupação do solo (sistemas de polígonos), estradas (polilinhas) e limite da microbacia (polígono) (TEIXEIRA et al., 1965). As informações digitalizadas foram editadas, separadamente, pelo software CARTALINX. Com os mapas editados procedeu-se a entrada dos dados no programa IDRISI FOR WINDOWS (Figura 2).

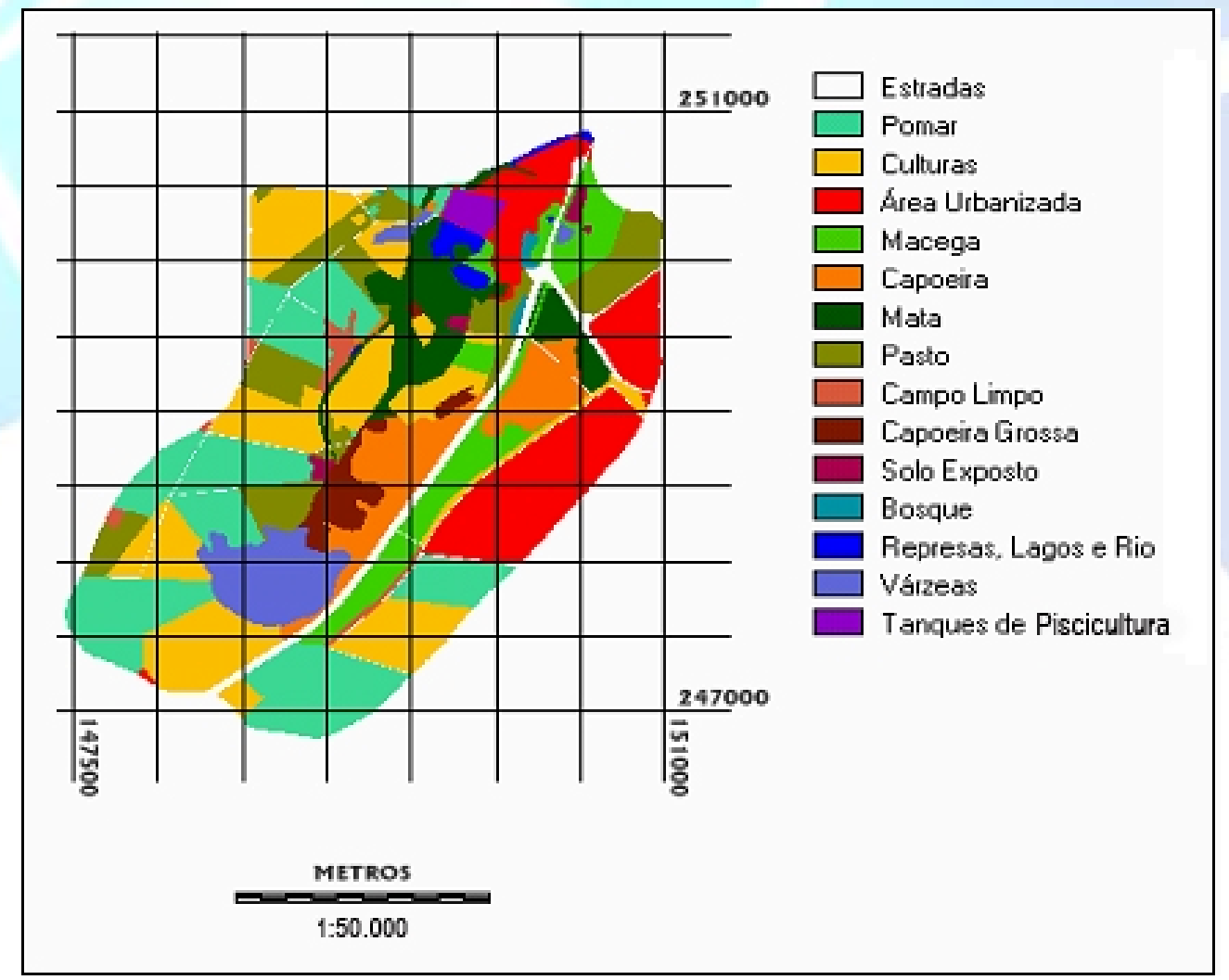

Figura 2. Mapa do uso e ocupação do solo da microbacia do córrego da Barrinha, 2005. Pirassununga/SP.

Fonte: Bufon (2006). 


\section{RESULTADOS E DISCUSSÃO}

Os estudos estão sendo realizados desde 1990 sobre o levantamento das áreas rurais limítrofes ao ICMBio/MMA, tipos de cultura, conservação de solos, defensivos agrícolas, os quais podemos verificar através de registros de fotos.

Nos locais preparados para o plantio de soja, observa-se que não foram feitas curvas de nível, fato totalmente em desacordo com os preceitos da técnica de conservação do solo e, também, a existência de formação de sulcos de erosão, com a terra escoando para a várzea, tendo inclusive, assoreado o plantio de arroz que ocupa faixa marginal da várzea (MENDONÇA et al., 1990) (Figura 3).

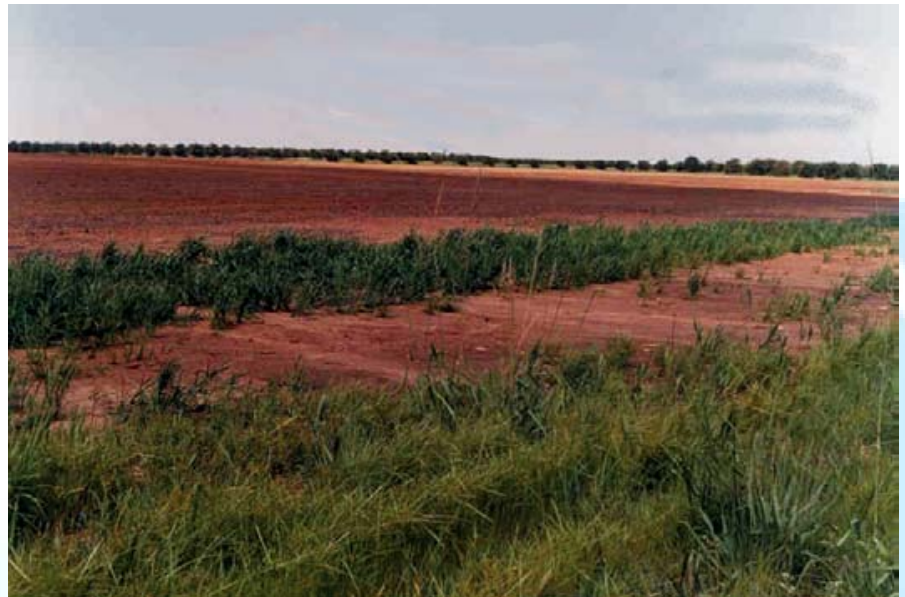

Figura 3. Terra preparada para o plantio de soja a montante da nascente do córrego da Barrinha, 1990. Pirassununga/SP. Fonte: Mendonça et al. (1990).

A mineração de areia junto à bacia proporciona o carreamento de partículas sólidas para o córrego, durante o período chuvoso, provocando grande turbidez na água (MENDONÇA et al., 1990) (Figura 4).

Medidas de controle de sedimento em pequenas bacias podem ser diferentes para as de maior porte. Se a bacia não é muito grande, o efeito de conservação de solo pode ser sentido em curto tempo. As áreas de agricultura devem ter o controle de sedimentos por práticas adequadas de conservação e de manejo do solo. Entre essas práticas estão às plantações em contorno ou em curva de nível que exigem a aração também em curvas de nível. Além da plantação estar em curva de nível, convém que sejam preparados pequenos diques de altura de $30 \mathrm{~cm}$, em terrenos que sejam mais inclinados (CARVALHO, 1994).

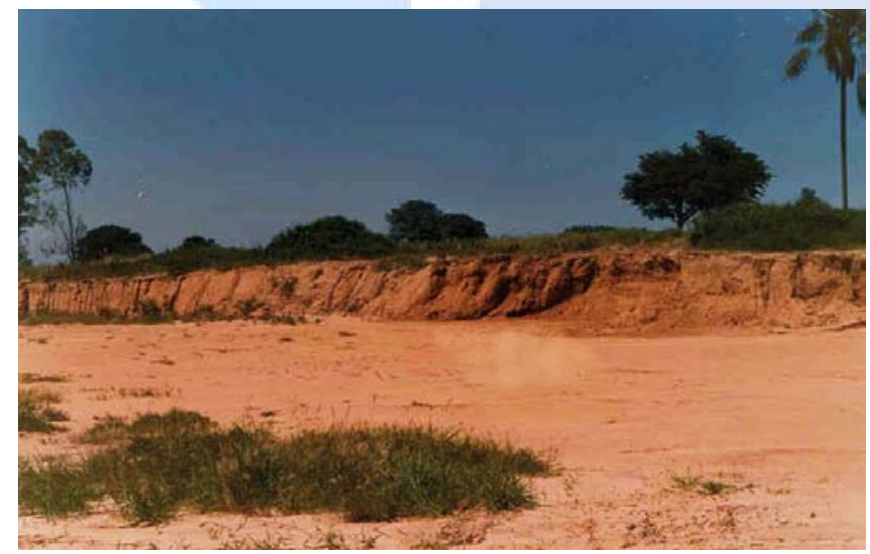

Figura 4. Mineração de areia junto à microbacia do córrego da Barrinha, 1990. Pirassununga/SP. Fonte: Mendonça et al. (1990). 
A região possui também uma pequena barragem, com alta turbidez da água, ocasionada pela total inexistência de práticas de conservação a montante, pelo plantio de cana-de-açúcar até a margem da barragem sem haver qualquer faixa de proteção. Conseqüentemente há carreamento de sólidos para a bacia, inclusive de defensivos e fertilizantes. Observa-se a falta de técnicas inadequadas para construção de barragem, aliado ao desconhecimento de técnicas de conservação de solo.

Observa-se também a existência de cultura de cítricos até a beira da barragem, sem faixa de proteção, ou de terraço para contenção de água, provocando violenta erosão. O rompimento possível desta barragem poderá acarretar conseqüências drásticas para o ICMBio/MMA, visto estar à barragem a montante da sua área. Além desses problemas a montante desta, a outra preocupação é com a terra preparada para cultivo (MENDONÇA et al., 1990) (Figura 5).

A inexistência de práticas conservacionistas nas atividades agrícolas observadas ao longo da microbacia do córrego da Barrinha é refletida principalmente na alta turbidez da água na represa Velha, o que por sua vez, ocasiona, como evidenciado por Mendonça et al. (1990), a mortalidade de larvas de peixes no período de chuvoso (Figura 6).

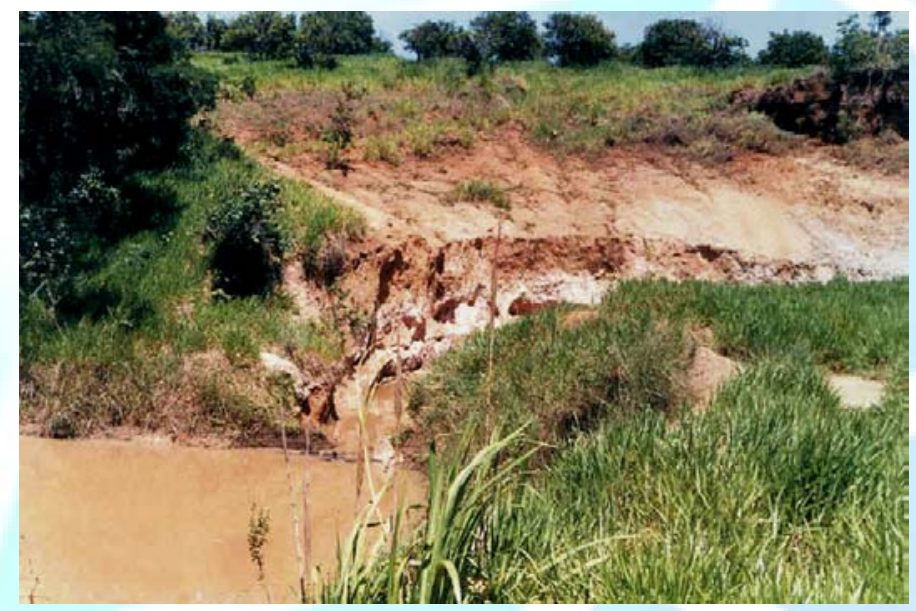

Figura 5. Plantio de cana-de-açúcar e cítricos até a margem da barragem a montante da represa Velha (Instituto Chico Mendes), 1990. Pirassununga/SP. Fonte: Mendonça et al. (1990).

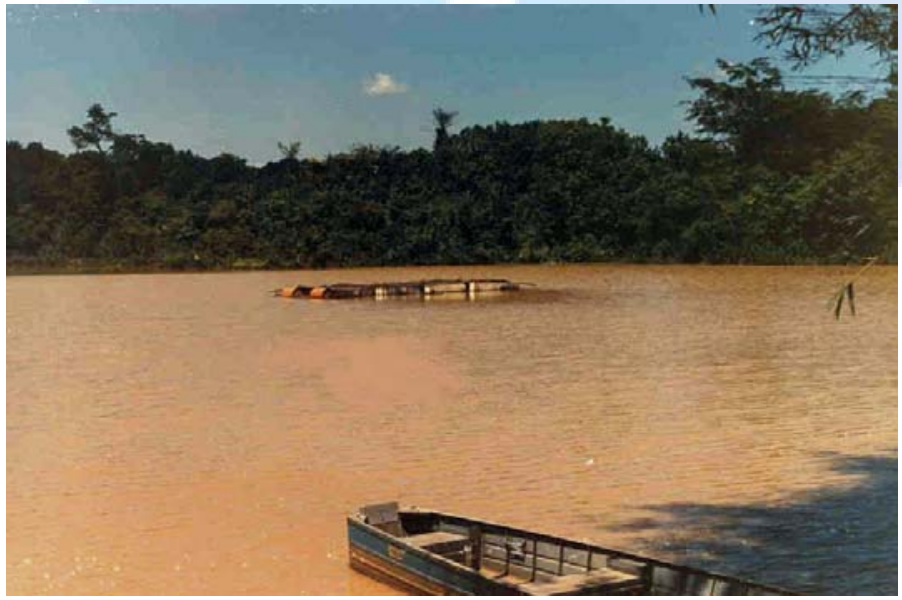

Figura 6. Represa Velha do Instituto Chico Mendes, com alta turbidez, observada em 1990. Pirassununga/SP. Fonte: Mendonça et al. (1990). 
Trabalho realizado por Silva et al. (1994) na microbacia listou alguns problemas, além dos anteriores observados por Mendonça et al. (1990). Por exemplo, observou-se que a área da nascente estava rodeada por solo preparado para cultivo de algodão, com restos de plumas do plantio anterior (Figura 7).

Também foi observado que a área de várzea onde estão localizadas as primeiras nascentes estava com a vegetação destruída por incêndio ocorrido em setembro de 1994. Havia vegetação inadequada ali plantada e drenos mal localizados e, ao fundo, culturas de laranja (SILVA et al., 1994) (Figura 8).

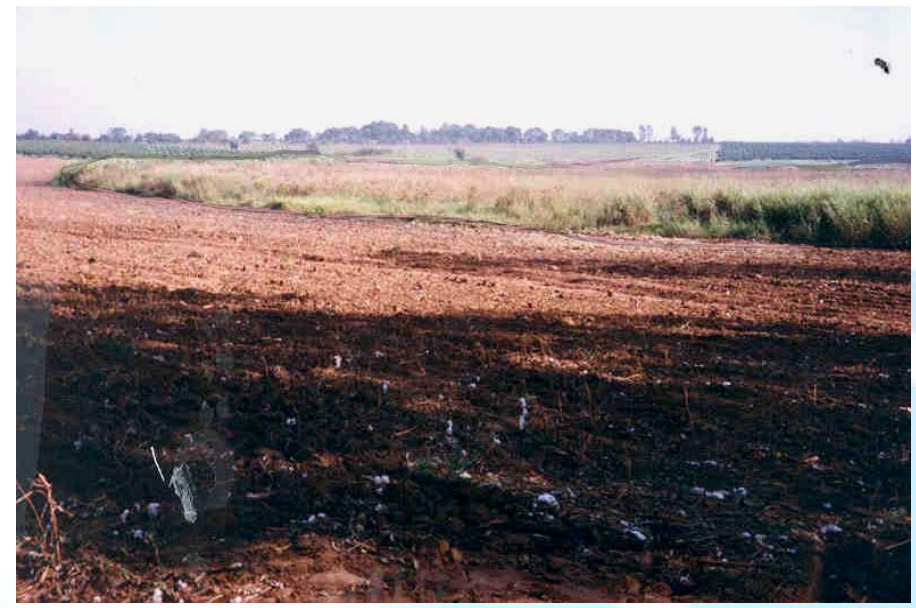

Figura 7. Contorno da área da nascente a montante da represa Velha (Instituto Chico Mendes), 1994. Pirassununga/SP. Fonte: Silva et al. (1994).

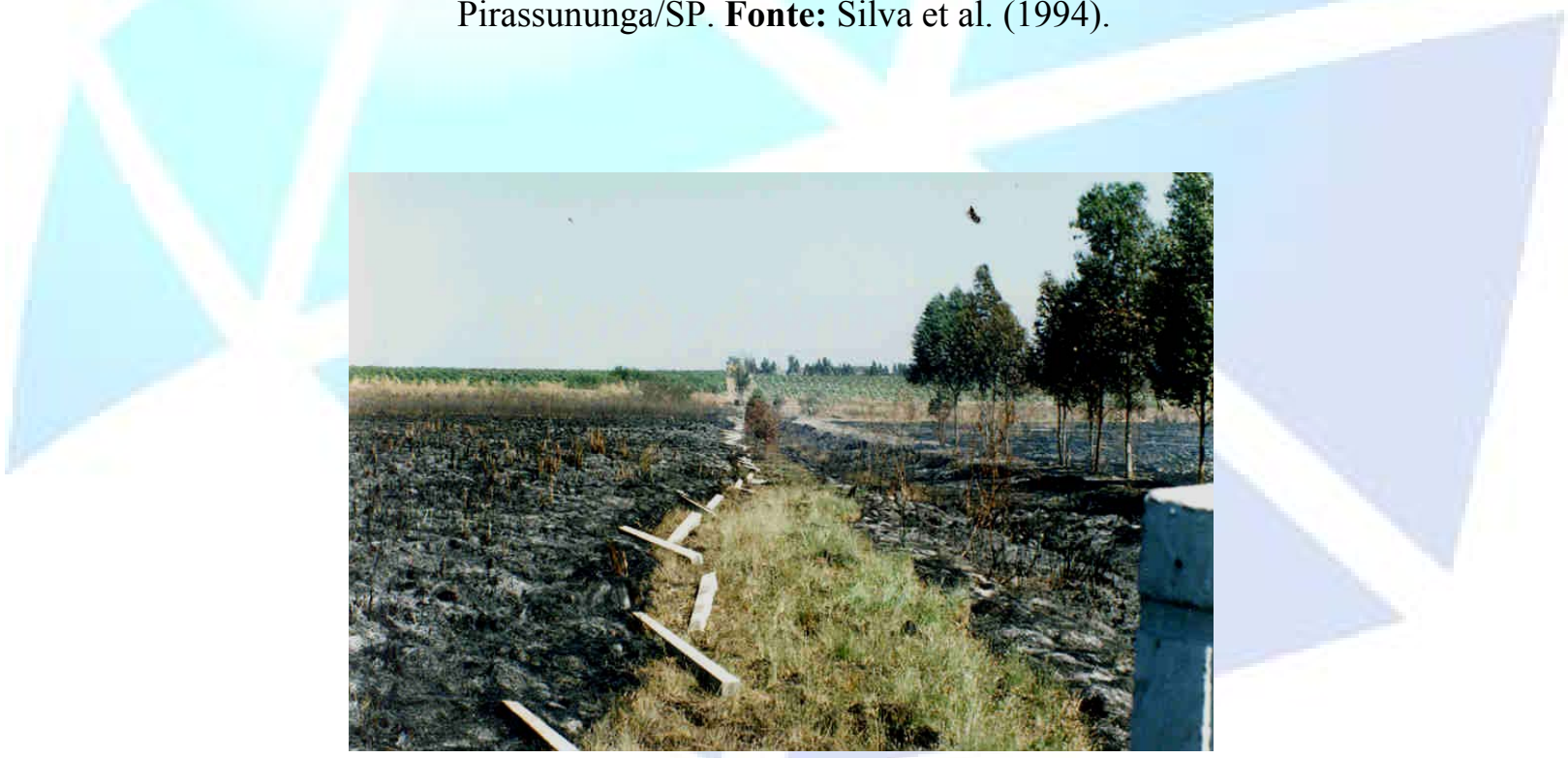

Figura 8. Área das nascentes com vegetação destruída por incêndio a montante da represa Velha (Instituto Chico Mendes), 1994. Pirassununga/SP. Fonte: Silva et al. (1994).

Na Figura 9, observa-se a atividade de mineração de areia na margem esquerda do córrego da Barrinha, não apresentando qualquer atividade de recuperação da vegetação ciliar, como já observado por Mendonça et al. (1990).

Existe uma área à direita do córrego, no médio curso (Figura 10), apresentando terreno inclinado, solo com textura arenosa e técnicas inadequadas de cultivo de cana-de-açúcar, havendo risco potencial de carreamento de material arenoso e início de erosão, aumentando o assoreamento do corpo hídrico (SILVA et al., 1994). 


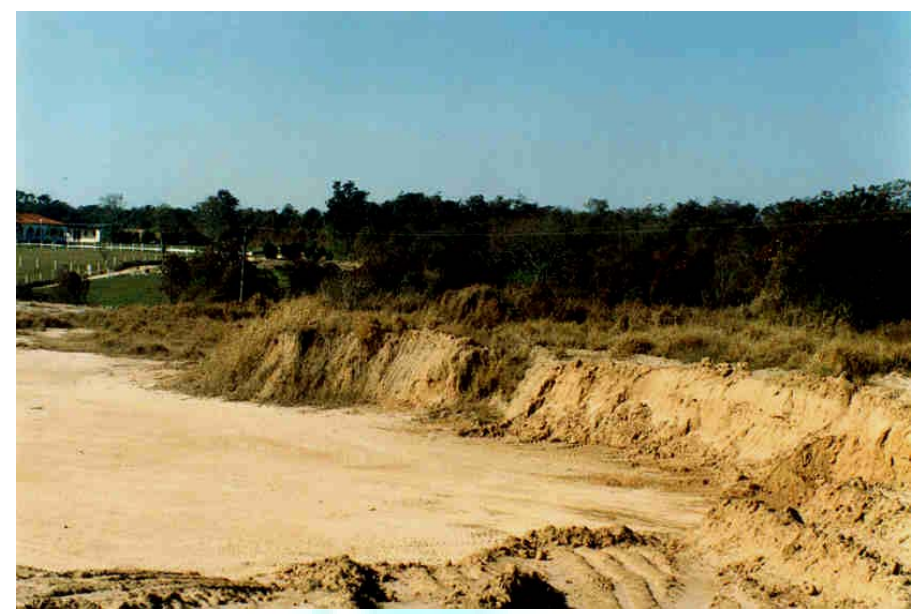

Figura 9. Mineração de areia a margem do córrego da Barrinha, 1994. Pirassununga/SP. Fonte: Silva et al. (1994).

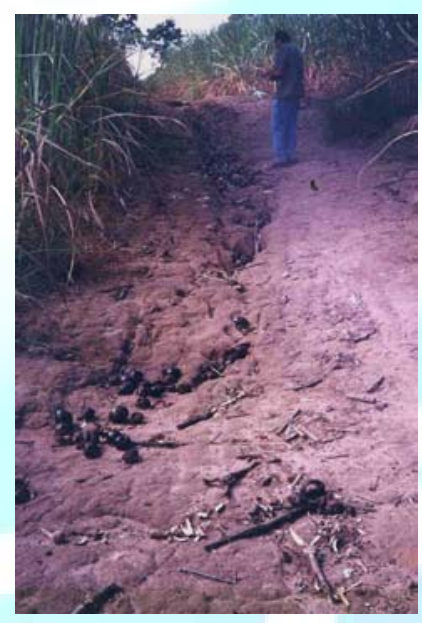

Figura 10. Carreamento de material arenoso para o córrego da Barrinha, 1994. Pirassununga/SP. Fonte: Silva et al. (1994).

O carreamento de solo, devido ao uso de práticas inadequadas de conservação do solo, proporcionou o assoreamento da represa Velha. Em julho de 1994, foi realizada uma atividade de esvaziamento desta represa, evidenciando-se o acúmulo de material carreado na entrada da represa, formando um delta (SILVA et al., 1994).

\subsection{Caracterização Vegetal}

As florestas não podem ser manejadas de forma a sofrerem desmatamento total. Embora tal restrição exista, não há que se falar da ausência de finalidade econômica na preservação dessas florestas, pois qual melhor investimento senão aquele que visa garantir, através da conservação dessas florestas, o bem estar da população, num sentido amplo. Mesmo porque, ao se preservar tais formas de vegetação, protege-se o solo dos processos erosivos, preserva-se a fauna e a flora.

O solo quando privado de sua cobertura florestal fica modificado em sua estrutura e perde as propriedades físico-químicas capazes de garantir a retenção de água. A vegetação existente ao longo dos rios funciona como um obstáculo natural ao escoamento das águas que ficam retidas e são absorvidas, em grande parte, pela mata, evitando que uma quantidade exagerada de partículas sólidas seja arrastada e depositada no leito dos rios. 
Além de evitar o assoreamento do leito dos rios, a mata ciliar consiste em um ecossistema peculiar que abriga uma diversidade florística e faunística de vital importância para o equilíbrio de toda uma região. Além de proteger indiretamente a fauna aquática, pode evitar o transporte de resíduos de agrotóxicos utilizados largamente na agricultura, os quais, na ausência da mata ciliar, são arrastados para os rios ocasionando, não raras vezes, a morte de peixes e de outros organismos aquáticos provocadas em função da poluição.

No córrego da Barrinha a atividade antrópica que tem maior influência na mata ciliar são as culturas temporárias com $18,0 \%$ sobre a área total, tendo a área urbanizada em segundo lugar com $14,3 \%$ e a cana de açúcar com 15,1\%. As culturas temporárias são os locais onde ocorrem rotações de cultura como soja, milho e algodão. Apesar da mineração ter um valor menor que $1 \%(0,2 \%)$, sua atividade tem poder de degradação muito grande, visto que ocorre nesta área extração de areia (SILVA, 2000).

Um dos grandes problemas decorrentes da degradação da mata ciliar é o acentuado escoamento superficial de resíduos para o leito dos rios e, nesta região, isto já está ocorrendo conforme análise feita por Bufon (1999) na represa Velha, que se encontra na área interna do ICMBio/MMA, observando-se que em 60 anos houve uma perda de $70 \mathrm{~cm}$ de profundidade da mesma, devido a deposição de sedimentos ao longo do córrego da Barrinha.

No local de estudo existe a Formação Pirassununga composta por areias e conglomerados da era Cenozóica e do período Terciário. Já a formação geológica de Intrusivas Básicas corresponde aos diabásios da era Mesozóica e do período Jura-Cretáceo que dão origem ao latossolo roxo.

Essa área tem maior porcentagem de uso na atividade agrícola, pois, somando-se as classes de culturas temporárias, cana-de-açúcar e laranja, correspondendo a 46,5\% do total da área da microbacia (SILVA, 2000). Guerra (1999) afirmou que o volume de material erodido é muito maior nos campos agrícolas arenosos do que nos argilosos, e isto pode ser apontado pelo papel da textura na erodibilidade dos solos.

\subsection{Caracterização geomorfológica da microbacia do córrego da Barrinha e sua susceptibilidade erosiva}

A localização da Microbacia lhe confere morfologia caracterizada predominantemente por relevo suave, colinas escarpadas no domínio de Cuestas, vales dissecados, com baixa amplitude altimétrica, donde registram cotas não superiores a $850 \mathrm{~m}$ e vale em torno de $500 \mathrm{~m}$, cabendo ressaltar tratar-se do nível de base de dissecação do rio Mogi-Guaçu, principal bacia regional.

O município de Pirassununga se encontra assentado sobre assoalho geológico representado por sedimentos mal consolidados, de idade cenozóica. Localiza-se no contexto geomorfológico regional, em área de interface entre a Depressão Periférica Paulista e o domínio de Cuestas ArenitoBasálticas, por litotipos do Grupo São Bento, cabendo ressaltar a ocorrência de extensas áreas com predomínio de material decorrente de pedogênese em rocha básica, onde se prescreve área de ocorrência de sills de diabásio.

Quanto ao solo, verificam-se grandes manchas de terra roxa estruturada, inclusive sob a malha urbana, além da ocorrência de solos em estágios pedogenéticos diferenciados sob litotipos da Formação Pirassununga. O rio Mogi-Guaçu, em seu médio curso, drena assoalho geológico representado por sedimentos de origem deposicional recente, sendo que na área, tema desta pesquisa, apresenta seu leito sobre sill de diabásio (Formação Serra Geral), onde se observa a formação de corredeiras. A microbacia do córrego da Barrinha drena o assoalho acima descrito, onde se registra, da pedogênese sobre o diabásio que decorre a terra roxa estruturada, presente em toda a extensão leste da microbacial.

$\mathrm{Na}$ área de abrangência, a morfologia da superfície neste caso é representada por vale côncavo, em área de coalescência entre o córrego da Barrinha e o rio Mogi-Guaçu, de gradiente insipiente, com declividade em torno de $2 \%$, situação verificada em todo baixo curso do manancial. 
Sob a fase argilosa observada nesta superfície, ocorrem dois níveis fundamentais de depósitos: alúvios coluvionares, cuja ação pedogenética diferencial evidencia lentes de cascalho intemperizado, e fração granulométrica do quartzo com diâmetro entre $1 \mathrm{~mm}$ e $4 \mathrm{~mm}$.

Interposta ao domínio da terra roxa constata-se a ocorrência de latossolos oriundos do intemperismo sobre sedimentos predominantemente arenosos a areno argilosos da Formação Pirassununga, de idade Cenozóica (GALIANO, 2001). Essa formação é constituída por sedimentos arenosos inconsolidados, não estratificados e sem estrutura, verticalmente homogêneos, sobrepostos indiferentemente às formações mais antigas. Sua espessura provavelmente não ultrapassa vinte metros e dispõe-se de modo descontínuo.

A coloração predominante dos sedimentos é marrom avermelhada, com baixo grau de seleção, contendo minerais argilosos, grãos de quartzo com vários índices de arredondamento, às vezes com película de óxido de ferro secundário e minerais máficos. $O$ seu ambiente de sedimentação seria de origem continental. A formação, ora descrita, encontra-se provavelmente sobreposta às Intrusivas Básicas (Grupo São Bento) e ocorre na forma de sill de diabásio, e também de afloramentos pontuais (GALIANO, 2001) (Figura 11).

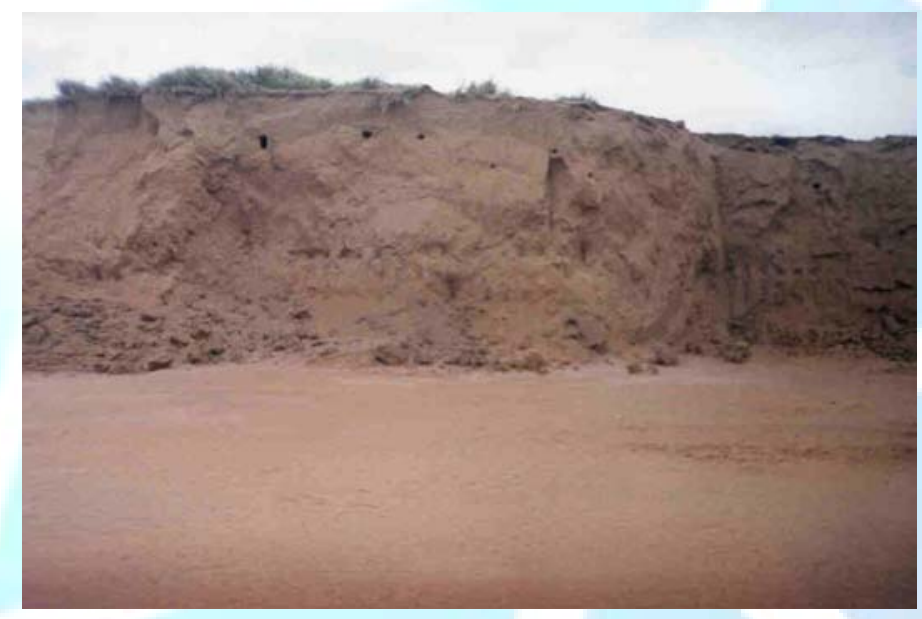

Figura 11. Solo da Formação Pirassununga, área de mineração de areia na microbacia do córrego da Barrinha, 1998. Pirassununga/SP.

Tais sedimentos abrangem cerca de $80 \%$ da microbacia, correspondendo ao assoalho dos setores de alto e médio curso do córrego da Barrinha. No setor de alto curso, de morfologia côncava, observam-se nichos de nascentes que confluem em represamento natural junto ao topo do interflúvio, onde o componente pedogenético é representado predominantemente por solos em estágio adiantado de hidromorfismo (Figura 12). No entorno desta área, ainda junto ao alto curso do manancial, as vertentes, de morfologia convexa, apresentam gradiente insipiente, onde as classes de declive variam entre $2 \%$ e $5 \%$ (GALIANO, 1998).

A morfologia de superfície, que em toda a extensão da microbacia registra classes de declives nunca superiores a $20 \%$, associada ao manejo do solo, ainda que prevaleçam as culturas temporárias, respondem pelo predomínio da erosão laminar nas propriedades, em relação à ocorrência de sulcos, ravinas e voçorocas, processos constatados principalmente junto ao terraço fluvial, em setor de leito encaixado. 


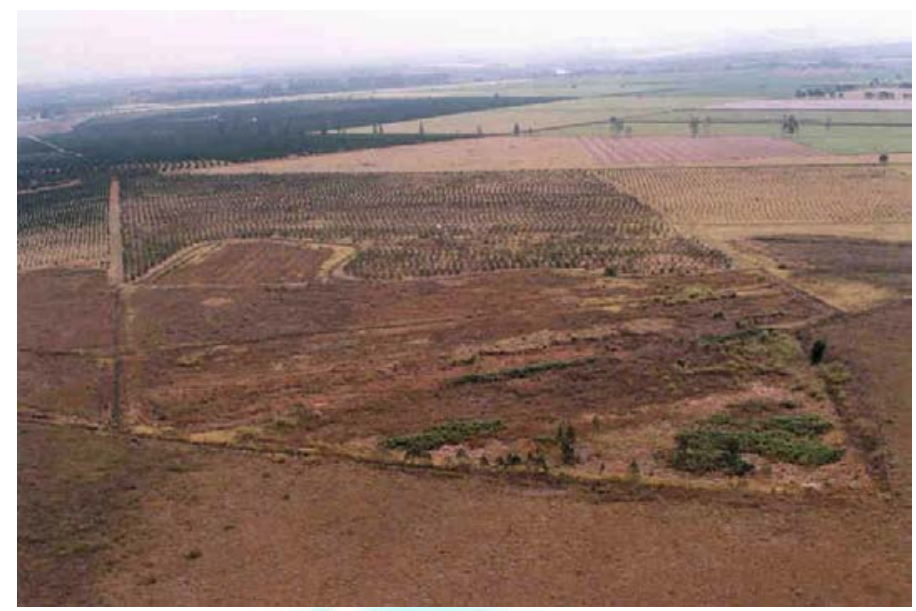

Figura 12. Área de nicho de nascente na microbacia do córrego da Barrinha, 1998. Pirassununga/SP.

O desenvolvimento de processos erosivos é comumente deliberado, entre outros fatores, pelas características topográficas, litológicas, de uso do solo e pedológicas, que mediante a urbanização, vão apresentar seu potencial morfodinâmico alterado, inibindo ou intensificando o desencadeamento de tais processos. Neste contexto, a investigação da aptidão natural à ocupação nos espaços periurbanos e ou na zona rural, representa prerrogativa importante na orientação de ações de planejamento, bem como de procedimentos mitigadores de impactos ambientais. Referindo-se aqui à situação de perda de solo, ocasionada principalmente pelo manejo mal orientado, como carreadores sem curvas de nível ou pela prática agrícola em zonas de preservação permanente, fatores que tendem a contribuir para a perda de solo fértil, bem como intensificar o assoreamento de canais (Figura 13).

A bacia hidrográfica em estudo apresenta duas práticas principais de uso do solo, com predomínio de plantios perenes e intermitentes nos setores de alto e médio curso, e, no setor de baixo curso, 8 laboratórios e demais edificações que compõem a estrutura administrativa e funcional do ICMBio/MMA, além de duas represas, a represa Velha e a represa Nova, que abastecem cerca de 129 tanques e viveiros de piscicultura (Figura 14).

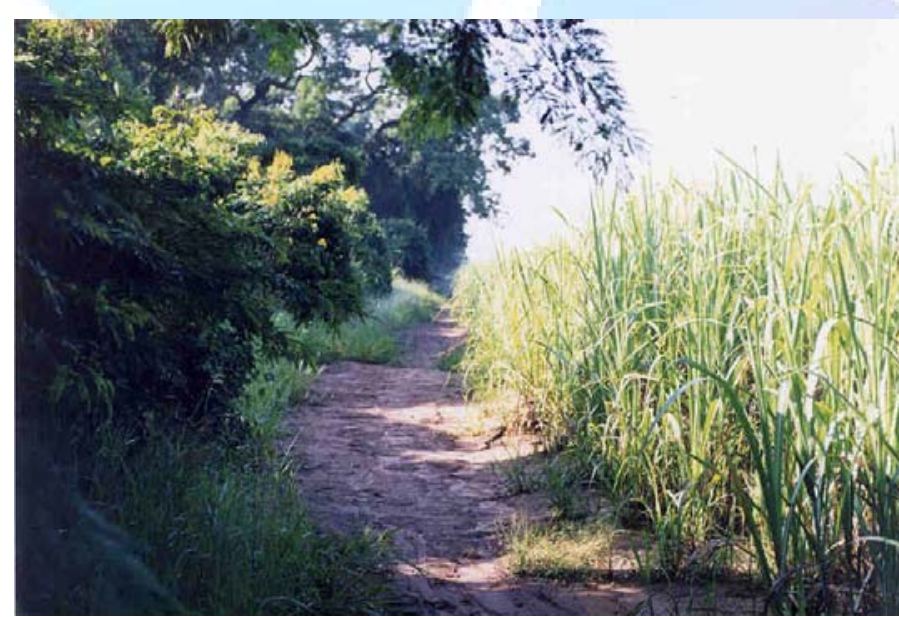

Figura 13. Carreamento de material arenoso para o córrego da Barrinha, devido manejo mal orientado, 2002. Pirassununga/SP. 


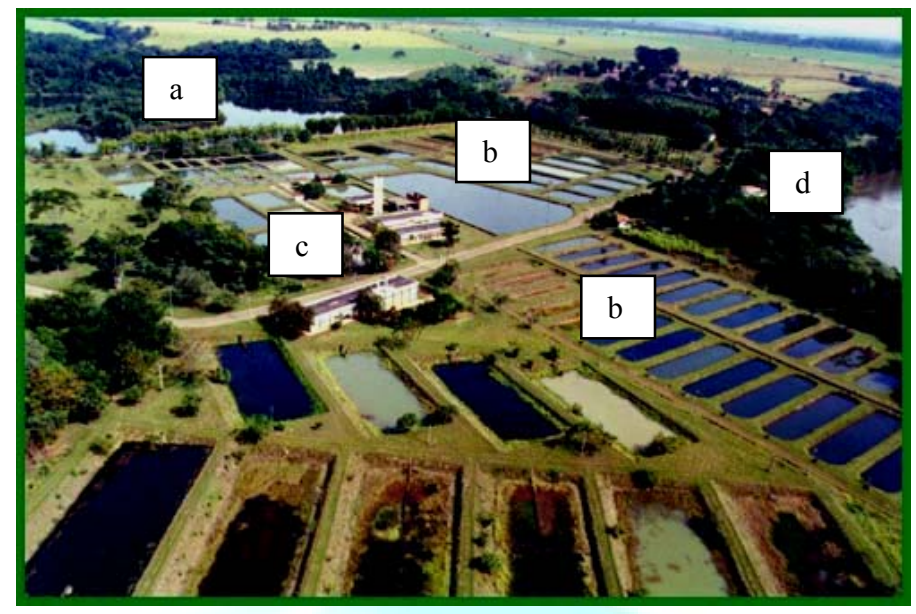

Figura 14. Vista aérea da microbacia do córrego da Barrinha, mostrando a represa Velha. Legenda: (a) - represa Velha, (b) - tanques e viveiros de criação de peixes, (c) - laboratórios e (d) - rio MogiGuaçu, 1998. Pirassununga/SP.

Tais represas representam o principal nível de base para a contribuição sedimentológica de montante, cabendo, portanto, a análise dos fatores intervenientes no assoreamento destas unidades, a avaliação do manejo do solo e alterações no percurso do flúvio. As avaliações visam dar subsídios para identificação dos principais fatores responsáveis pelos índices de assoreamento verificados na represa nos últimos anos, bem como, conduzir a proposições visando minimizar esta situação.

Partindo desta ótica, consideram-se as características dos solos que ocorrem na microbacia, além dos aspectos referentes à tipologia, a suscetibilidade erosiva do manto de alteração, tomando como referência as variações anisotrópicas verticais e horizontais apresentadas e, fundamentalmente, o uso do solo.

\subsection{Uso e ocupação do solo}

A área de estudo apresentava predomínio de cultura temporária fundamentalmente na área de alto curso, em setores cuja morfologia, conforme descrita acima, apresenta declividade pouco acentuada. Havia neste contexto a ocorrência de plantio de milho, algodão e painço, em área de coalescência, junto ao interflúvio principal do córrego e o nicho de nascentes.

As características de declive (insipiente) bem como a incidência de área côncava, traçada pela abrangência do charco no setor de nascentes, com o raio, cerca de $100 \mathrm{~m}$, compreendem fatores deliberativos para a acomodação do material decorrente da lixívia de superfície, que tende a se concentrar nesta área de embaciamento. As características morfológicas e de morformétricas compreendem fatores deliberativos para o controle da contribuição sedimentológica, decorrente de processo erosivo laminar para jusante.

$\mathrm{Na}$ área de média alta vertente existe o cultivo de cultura perene, representada pela citricultura $(13,4 \%)$, que, com a propriedade de cobertura do solo, em função das copas, contribui para a menor incidência erosiva na área de sua abrangência.

Nos setores de médio e baixo curso, sobre os diques marginais do córrego e terraços recente e sub-recente, verifica-se domínio de mata ciliar e galeria $(6,4 \%)$, a propriedade de contenção erosiva da mata é rompida somente em pequenos trechos onde se constata, em perfil fluvial encaixado, supressão da cobertura vegetal (Figura 15). 


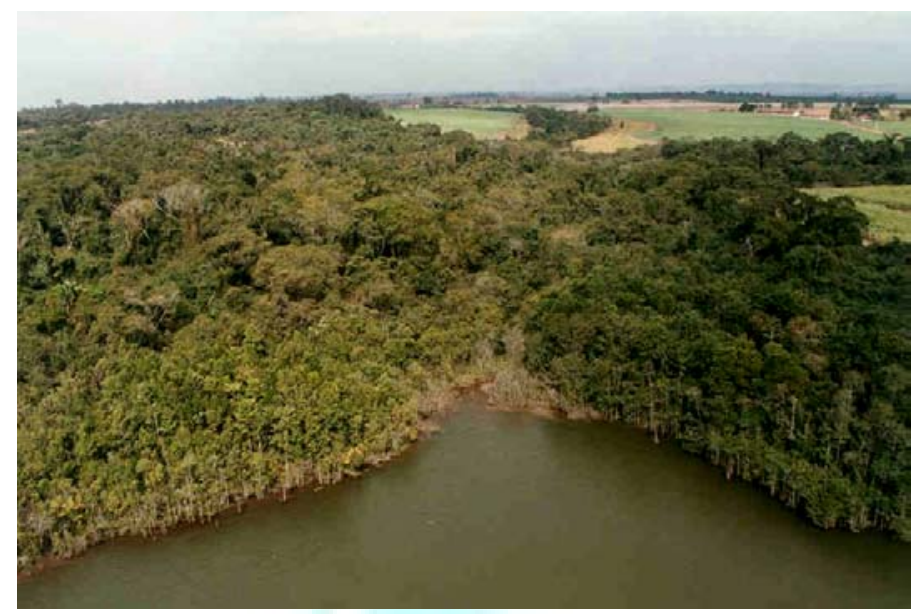

Figura 15. Mata galeria junto a cava do córrego da Barrinha e cultivo de cana-de-açúcar, a montante da represa Velha (Instituto Chico Mendes), 1998. Observa-se a falta de preservação da mata ciliar na encosta do vale (área mais clara). Pirassununga/SP.

Neste setor ocorre a presença de erosões regressivas em taludes, marcadas por sulcos em ravinas, pronunciados em áreas de terraço recentes. De acordo com a antiga proprietária, o cultivo de laranja foi substituído por cana-de-açúcar e lavra de extração de areia a céu aberto. O minério é retirado do solo e removido para um local determinado. A seguir é retirado através de caminhões para ser comercializado.

Nos setores de vertente, pela margem direita, observam-se dois compartimentos morfométricos característicos, representados por topo plano, e pela margem esquerda, as características morfológicas do córrego da Barrinha. Na vertente direita, têm-se em área de topo duas categorias de parcelamento de solo, onde se observa o uso de glebas agrícolas lindeiras (vizinhas, confrontantes) à área urbanizada, vila Santa Fé.

O setor agrícola apresentava cultura perene, prevalecendo também neste caso, o cultivo da laranja. Ressalta-se que o deflúvio de superfície tem estrangulamento promovido por uma pista de rolamento "SP 201 - Rodovia Prefeito Euberto Nemésio Pereira de Godoy", que corta a microbacia no sentido Norte-Sul (3,7\%).

A contribuição de água deste setor não atinge as áreas de média a média baixa vertente pela margem direita do córrego da Barrinha, situação que redime o carreamento de sedimentos para o manancial. Já nos setores de vertente ocorre a predominância de mata ciliar, galeria e, próximo à rodovia, o domínio de cerradão $(8,1 \%)$. Esse tipo de vegetação promove a proteção do corpo de água, funcionando como um sistema de filtro. Parte da água que chega via precipitação é retida pelas raízes da vegetação e infiltra-se.

Os nutrientes e materiais oriundos de lixos e outras fontes são retidos pelas vegetações próximas à rodovia; o que não é retido pela primeira vegetação fica na segunda e assim sucessivamente. Desta forma justifica-se a preservação deste tipo de vegetação ao longo dos rios e demais corpos de água.

Cabe concluir que o uso do solo nos setores de média e média baixa vertente do córrego da Barrinha, pela margem direita, em função da cobertura vegetal preservada, inibe o desenvolvimento de processos erosivos, situação resguardada também pelo corte da estrada, Rodovia SP 201 (Figura 16). 


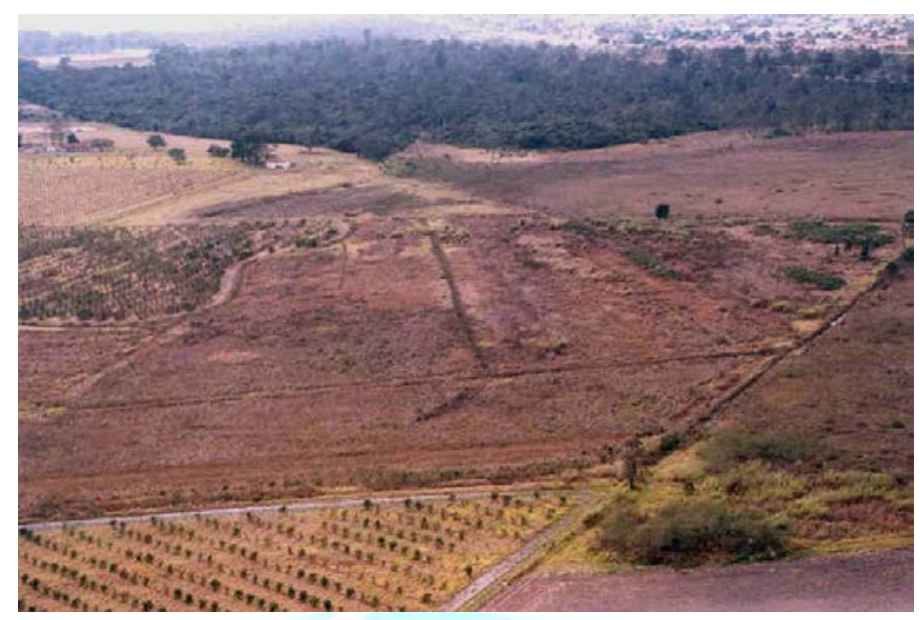

Figura 16. Mata da microbacia do córrego da Barrinha a montante da represa Velha (Instituto Chico Mendes - ICMBio/MMA), 1998. Pirassununga/SP.

$\mathrm{Na}$ vertente esquerda, a morfologia predominantemente côncava constata-se que neste setor ocorreu predomínio de cultura perene, representada pelo plantio de laranja, que perdurou de 1988 até 1992, quando a laranja cedeu espaço ao cultivo de milho e algodão. Neste contexto de uso do solo verifica-se que o potencial das áreas para o desencadeamento de processos erosivos (erosão laminar) vem sendo intensificado, situação pertinente ao plantio intermitente. Tendo-se neste caso períodos de solo nu, característicos do manejo.

Esse quadro tem como fator amenizador os baixos índices de declive, onde se verifica predomínio de valores entre 2 e 5\%. Na contenção da contribuição sedimentológica das vertentes compreende a área de nicho de nascentes, com a morfologia, conforme já foi ressaltada, favorecendo a concentração de sedimentos nesta área.

Em direção ao vale fluvial com a morfologia côncava, observa-se o plantio de cana-deaçúcar, onde a ocorrência do solo nu dentro da prática de manejo proporciona condições de lixívia que também terá sua intensidade reduzida em função do baixo gradiente do terreno. No setor de médio curso, com morfologia predominantemente convexa em área de topo e média vertente, o plantio de cana-de-açúcar, ressaltado anteriormente, terá a contribuição de interflúvio inibida pela declividade.

Em todo setor de médio curso em área de vertente há o predomínio de cana-de-açúcar, onde, assim como no compartimento geomorfológico anterior, a morfologia e os índices de declividade reprimem a intensidade da lixívia horizontal. Tem-se ainda que a cana é plantada em curva de nível fora do recuo da Área de Preservação Permanente (APP).

No setor de coalescência de ambas as margens constata-se presença de mata ciliar em trecho onde o vale fluvial ainda permanece encaixado. Junto ao baixo curso pela margem esquerda constatou-se que até a década de 80 havia o predomínio de pastagem, hoje também substituída por cana-de-açúcar.

Neste setor observa-se também uma pequena contribuição por deflúvio. O vale fluvial em todo o baixo curso apresenta cobertura vegetal representada por mata ciliar e galeria sob sedimentos predominantemente arenosos de terraços recentes e sub-recente do córrego da Barrinha.

Neste setor a vegetação representa a principal variável na contenção de processos erosivos, uma vez que, em que pese o baixo gradiente, a composição textural do pacote alúvio coluvionar do terraço apresenta grande susceptibilidade ao transporte tanto pela água da chuva como pela ação erosiva ocasionada pelo próprio córrego.

Observa-se que o desvio provocado no leito natural do córrego, visando o escoamento da represa para a retirada dos peixes, procedimento que conduziu o manancial para setor de terraço 
arenoso, com supressão de vegetação, resultou em uma grave intensificação da erosão neste setor, causando inclusive o recuo de margem. Tal quadro compreende a principal causa do aumento do assoreamento na represa Velha.

As informações foram obtidas através de entrevistas informais com os antigos e atuais proprietários, além de visita a cada propriedade, considerando três grandes unidades para a microbacia do córrego da Barrinha, setor de alto curso, médio curso e baixo curso. Atualmente, observa-se forte tendência de substituição de todas as culturas por monocultura de cana-de-açúcar em toda a bacia do Córrego da Barrinha.

\section{CONCLUSÕES}

Ainda que pese o manejo de culturas que propiciavam condições de solo nu durante alguns meses do ano, as características morfológicas e de morformetria compreendem fatores deliberativos para o controle da contribuição sedimentológica, os quais, decorrentes de processo erosivo laminar nas propriedades, promoveram a ocorrência de sulcos, ravinas e voçorocas a jusante. Ocorre também presença de erosão regressiva em taludes, marcada por sulcos em ravinas, pronunciadas em área de terraço recente.

A situação de perda de solo, ocasionada principalmente pelo manejo mal orientado ou pela prática agrícola em zonas de preservação permanente, como o nicho da nascente, são fatores que tendem a contribuir para a perda de solo fértil. O plantio de cana-de-açúcar e a prática da mineração de saibro intensificam o assoreamento no canal do córrego da Barrinha.

As informações contidas neste trabalho poderão auxiliar na elaboração de políticas ou medidas de conservação da área da bacia em estudo, como a criação de uma Área de Proteção Ambiental (APA) ou outra categoria de unidade de conservação de uso sustentável federal, conforme estabelece a Lei No 9.985/2000 (BRASIL, 2000).

\section{AGRADECIMENTOS}

Ao Instituto Chico Mendes de Conservação da Biodiversidade - ICMBio/MMA e ao Curso de Pós-Graduação em Geociências e Meio Ambiente da Universidade Estadual Paulista (UNESP), Campus de Rio Claro - SP, pelo apoio e estrutura utilizados para a realização deste trabalho, e à FAPESP, pela bolsa concedida (Processo $n^{\circ}$ 02/10143-9).

\section{REFERÊNCIAS}

BRASIL. Lei $\mathbf{n}^{\mathbf{0}}$ 9.985, de 18 de julho de 2000. Regulamenta o art. 225, $\S 1^{\circ}$, incisos I, II, III e VII da Constituição Federal, institui o Sistema Nacional de Unidades de Conservação da Natureza e dá outras providências. Diário Oficial [República Federativa do Brasil], Brasília, DF, n. 138, 19 jul. 2000. Seção 1, p. 1-6.

BUFON, A.G.M. Variação da taxa de sedimentação na represa Velha (CEPTA/IBAMA/SP) e sua influência sobre as características limnológicas do sistema. Um estudo de impacto ambiental, Pirassununga/SP. 1999. 80 f. Monografia (Trabalho de Conclusão do Curso de Engenharia de Agrimensura) - Faculdade de Engenharia de Agrimensura de Pirassununga, Pirassununga. 1999. 
BUFON, A.G.M. Estudo do assoreamento e sua relação com a vida útil do reservatório "represa Velha", Pirassununga/SP. 2006. 316 f. Tese (Doutorado em Geociências e Meio Ambiente) Instituto de Geociências e Ciências Exatas, Universidade Estadual Paulista - Rio Claro. 2006.

CARVALHO, N.O. Hidrossedimentologia prática. Rio de Janeiro: CPRM, 1994. 372p.

DUNNE, T.; DIETRICH, W. Sediment sources in tropical drainage basins. In: SOIL EROSION AND CONSERVATION IN THE TROPICS. Papers were presented during meetings in Fort Collins, Colorado, 1979. (ASA- Special Publication, 43) Madison: AMERICAN SOCIETY OF AGRONOMY Soil Science Society of America, 1982 p. 41-55.

GALIANO, V. A. Aplicação de um sistema de informações geográficas (SIG) na microbacia do córrego da Barrinha, para confecção de carta de uso do solo. 1998. $27 \mathrm{f}$. Monografia (Trabalho de Conclusão de Curso de Engenharia de Agrimensura) - Faculdade de Engenharia de Agrimensura de Pirassununga, Pirassununga. 1998.

GALIANO, V.A. Mapeamento geotécnico da quadrícula de Pirassununga (SP) na escala 1:50.000, como subsídio ao planejamento do meio físico. 2001. $140 \mathrm{f}$. Dissertação (Mestrado em Engenharia Urbana)-Centro de Ciências Exatas e de Tecnologia, Universidade Federal de São Carlos, São Carlos. 2001.

GUERRA, A.J.T. Planejamento ambiental em microbacia hidrográfica. In: GUERRA, A.J.T. et al (Org.). Erosão e conservação dos solos: conceitos temas e aplicações: Rio de Janeiro: Bertrand Brasil. 1999. p.17-50.

KLEEREKOPER, H. Estudo limnológico da Bacia do rio Mogi-Guaçu. Observações sobre a represa da Estação Experimental de Caça e Pesca do Ministério da Agricultura em Emas, SP. Rio de Janeiro: Serviço de Informação Agrícola, 1941. 63p.

LOMBARDI NETO, F.; CAMARGO, O.A. de. Microbacia do córrego São Joaquim (Município de Pirassununga, SP). Campinas: IAC, 1992. 138p.

SILVA, R.M. Caracterização ambiental da microbacia do córrego da Barrinha (Pirassununga - SP), utilizando geoprocessamento e o sistema topográfico local. 2000. 122 f. Dissertação (Mestrado em Engenharia Ambiental) - Escola de Engenharia de São Carlos, Universidade de São Paulo, São Carlos, 2000.

MENDONÇA, J.O.J.; SOUZA, J.H.; BERBARDINO, G.; LUCAS, A.F.B. Levantamento sobre propriedades limítrofes ao CEPTA: relatório sobre levantamento das áreas rurais limítrofes ao CEPTA, tipos de cultura, conservação de solo, defensivos agrícolas, Pirassununga:

CEPTA/IBAMA, 1990. 16p.

NASCIMENTO, V.M.C.; GALIANO, V.A. Aplicação de um sistema de informações geográficas para caracterização da microbacia do córrego da Barrinha, Pirassununga-SP. Boletim Técnico CEPTA, Pirassununga, v. 12, p. 71-79, 1999.

OLIVEIRA, A.M.S. Depósitos tecnogênicos e assoreamento de reservatórios. Exemplo do reservatório de Capivara, rio Paranapanema, SP/PR. 1994. 211f. Tese (Doutorado em 
Geografia) - Faculdade de Filosofia, Letras e Ciências Humanas, Universidade de São Paulo, São Paulo. 1994.

SILVA, V.; SOUZA, J.H.; NASCIMENTO, V.M.C.; FERRARI, V.A. Relatório microbacia do córrego da Barrinha: Pirassununga: CEPTA/IBAMA, 1994. 33p.

TEIXEIRA, C.; TUNDISI, J.G.; KUTNER, M.B. Plankton studies in a mangrove environment II. The standing stock and some ecological factors. B. Inst. Oceanography, USP, v. 24, p. 23-41, 1965. 